\title{
Global Brand Identity as a Network of Localized Meanings
}

\author{
Elizabeth S. Gunawan ${ }^{1} \&$ Paul van den Hoven ${ }^{1 \& 2}$ \\ ${ }^{1}$ School of Journalism and Communication, Xiamen University, Xiamen, China \\ ${ }^{2}$ Utrecht School of Linguistics, Utrecht University, Utrecht, The Netherlands \\ Correspondence: Elizabeth S. Gunawan, School of Journalism and Communication, Xiamen University, Xiamen, \\ China.E-mail: elizabeth.susanti@yahoo.com or p.vandenhoven@uu.nl
}

\author{
Received: January 12, 2017 Accepted: February 5, 2017 Online Published: March 2, 2017 \\ doi:10.5539/ijms.v9n2p56 URL: http://doi.org/10.5539/ijms.v9n2p56
}

\begin{abstract}
In this article, we develop a semiotic model to analyze advertisement glocalization. This model focuses on the mental representations that local audiences build of a "global" brand identity. We demonstrate how this model fills up gaps left by a popular marketing model for global advertising. We argue that the seemingly linear threestep marketing model implies several reciprocal processes in which meaning is developed and determined. This semiotic reinterpretation of the marketing model explains how a global brand identity maintains a dynamic relation with the actual brand identity that local customers construe. To illustrate the dynamics of the semiotic model, we analyzed localizations in the Snickers campaign "You're not you when you're hungry." Because the semiotic model elaborates the dynamics between the professionals' discourse used in developing a campaign and the localized "global" brand identities brought about in receiving the campaign, the model helps to explain anthropological dynamics in designing campaigns, the arising of locally differentiated "global" brand identities that are the result of global campaigns and the dynamic development of global campaigns.
\end{abstract}

Keywords: global brand, global campaign, glocalization, rhetoric, semiotics

\section{Introduction}

The mind of the market is in the customer (Zaltman, 2003; Zaltman \& Zaltman, 2008). With this insight into marketing theory, the relevance of a semiotic approach has been acknowledged in the field of brand theory (Note 1). Still, in literature about global branding, we observe a strong emphasis on the design of global campaigns (Keller, Apéria, \& Georgson, 2012; Van Auken, 2003). Execution and evaluation are conceptualized predominantly in terms of feedback on the initial goals of the professional campaign design. Localized versions of the campaign are analyzed in terms of adaptions of the global concept rather than as autonomous communications (Zhao \& Belk, 2008). The impact of localized "global" meanings on campaign development seems somewhat neglected (Note 2), as is the reflection on the fact that the "global brand identity" actually forms a complex network of related, localized meaningswith their own dynamics in a world connected by social media.

In this article, we have developed a semiotic model for advertisement glocalization. We demonstrate the value that this semiotic model adds to a popular marketing model. While the marketing model focuses on the professional rhetorical process when designing a campaign, the semiotic model concentrates on the audiences' interpretations of localized advertisements. It adds three important elements to the marketing model.

a. The semiotic model provides tools to elaborate the reciprocal interaction between the professional campaign design discourse and the resulting localized discourses.

b. The semiotic model provides tools to compare localized editions of a global campaign in a meaningful way, additional to understanding localized editions as derived from a global concept.

c. The semiotic model provides tools to connect the concept of a professionally designed global brand identity with a network of localized global brand identities as a result of the audiences' interpretations.

As a result, the semiotic model helps to explain anthropological dynamics in designing campaigns, locally differentiated "global" brand identities that are the result of campaigns, as well as the dynamic development of campaigns.

In section 2, we describe a popular marketing model for designing a glocalized global branding campaign. This 
model is representative for marketing models that focus on the professional design discourse and assume straightforward linear processes. In section 3, we develop a semiotic model for advertisement glocalization that fills up gaps left by the marketing model. To demonstrate the added value of the semiotic model, we have analyzed localizations of a global narrative of the Snickers campaign "You're not you when you're hungry", a campaign running in over 80 countries. In section 4, we introduce the Snickers campaign and elaborate on its rhetorical context. Its leading narrative employed humor and hyperbole to show the consequences of a temporal lack of energy and the capacity of the Snickers bar to restore the energy balance. In section 5, we compare the original American Super Bowl edition to a Chinese localized edition, taking other adaptations into consideration. Semiotic analysis reveals how the decision to maintain one narrative concept on a global scale forces one to make paradigmatic and syntagmatic choices to maintain localized social and cultural acceptability. As an inevitable result of these adaptations, localized audiences are guided towards partly different brand associations, which results in locally differentiated "global" brand identities. In section 6 , we reflect on the value of semiotic analysis for cross-cultural advertisement adaptation. Because localizations develop and determine the meaning of the global campaign concept, the model helps to explain rather autonomous campaign developments.

\section{A Marketer's Model of Glocalization}

The central problem of "glocalization" is the tension between global homogenization and cultural heterogeneity. This problem is particularly relevant in the process of global brand communication, in which a global brand intends to develop and maintain a global identity, while the commodification process differs among communities due to a wide number of social, cultural and economic factors. This often requires a localization of brand positioning and, therefore, also a localization of brand advertising (Zhao \& Belk, 2008).

In March 2013, Wind, Sthanunathan, \& Malcolm published an article in the Harvard Business Review that attracted a lot of attention: "Great advertising is both local and global" (Wind et al., 2013). They observed that "a poorly conceived ad in one market can damage the entire brand" and advocated "glocal advertising strategy - locally adapting a universally embraced core idea that will resonate in any market anywhere in the world." They formulated a straight forward three-step strategy to meet the challenge of glocal branding. First, find "a global concept that addresses a universal human motivation" and find a positioning that goes beyond describing product attributes to address this motivation. Second, develop "a unified brand vision with creative delivery that respects local nuances and empowers consumers in each locale." Third, develop "an organizational architecture, including culture, technological platform, and dedicated resources, that emphasizes and facilitates dynamic and effective collaboration between the developers of global strategy and local strategists and implementers."

According to Wind et al. (2013), implementing this strategy means that global brand management first conceptualizes the global brand identity. Then "the designers of global advertising strategy carry a creative concept most of the way to execution." Finally, "regional marketers tailor the work to make it locally relevant and aligned to the different brand situations at different places." They claim that "the framework respects and encourages local decision-making while at the same time supporting a unified brand identity."

We have based ourselves on this model because it represents the dominant approach in marketing theory (with Keller et al., 2012; Vanauken, 2003 as important examples) in taking the perspective of the brand manager and focusing on the top-down campaign design process. The straight forwardness of the approach of Wind et al. (2013) articulates our general argument. Obviously, this design process does not neglect the target audiences, but it exploits the results of elaborate marketing research, attempting to design a fit between the "universal human motivation" and what is known about the targeted customer audiences. This is why we call it a rhetorical process. The model largely omits to relate the concepts designed a priori to the actual mental representations of localized audiences. This is what a semiotic approach adds to the marketing model.

Wind et al. (2013) formulated the implementation of the strategy as a three-step linear process, which we summarized in Figure 1. Its linearity suggests that the meaning of the global creative concept precedes the actual localized communication processes and is rather independent from and unaffected by them. Figure 1, therefore, assumes a one-directional relation between an a priori concept of a global brand identity (the "unified brand vision") and a global concept that addresses a universal human motivation. The global brand management team communicates the global brand identity to the designers of a global campaign strategy in a professional discourse. It is assumed that the global brand identity sufficiently frames the design of a global campaign concept.

A one-directional relation is also assumed between the global concept that addresses a universal human motivation and the localized discourses. The campaign management team communicates the global concept to regional marketers, again in a professional, cross-cultural or inter-cultural discourse. It is assumed that the global 
concept sufficiently frames the production of localized discourses to make them part of one global campaign and to make sure that each of them has a good chance of construing a similar global brand identity in the minds of local consumers. In sum, the process starts with the professional conceptualization of a brand identity and ends with assuming that this identity has been construed in a localized audience on the basis of a localized discourse. Strong governance is assumed to "channel" the core meaning of the campaign all the way down, until it ends up, unimpaired, unchanged, uniform, in the mind of the local customer.

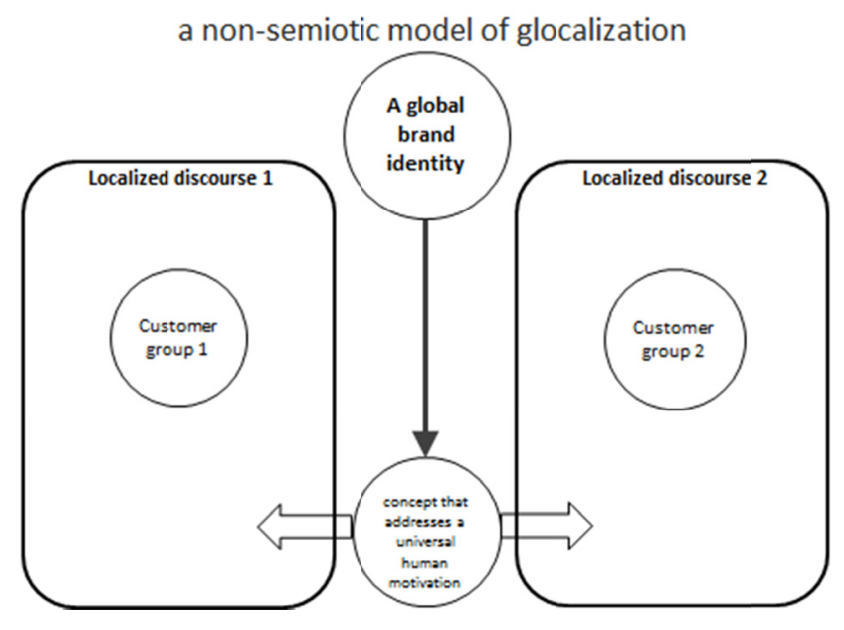

Figure 1. A non-semiotic model of glocalization

A semiotic analysis of this model reveals that there are a number of gaps in the model, predominantly resulting from questions concerning its linearity. The aim of our study is to fill up these gaps and demonstrate how the resulting semiotic model adds explanatory power to the "non-semiotic" marketing model.

\section{A Semiotic Model of Glocalization}

Some abstract conceptualization of a global identity will always precede a global campaign, and a campaign concept will indeed be formulated before an actual advertisement is produced. The meaning of the global concept, however, will only be articulated when localized discourse is produced. From a semiotic perspective, the meaning of the global concept is, in the end, a "network" of meanings attached by localized audiences to localized discourses: Every localization evokes an interpretation of the global concept and, therefore, develops and determines its "meaning." This fundamental step is absent from the marketing model represented in Figure 1.

Professional communication processes between brand management, campaign management, regional brand management and creatives will initially be abstract. The top-down coercive force of the global identity upon the global campaign concept as well as upon localized productions is often low and limited to abstract framing at first. The coercive force of local constraints, by contrast, as perceived by local management teams and creatives is high, due to differences in the outset situation, the target situation, the tools available and the meaning of such tools in the eyes of local management teams. How the professional, governance, top-down discourse is understood, furthermore, will be determined and developed in the minds of local designers predominantly influenced by their localized socializations. Local constraints, therefore, usually dominate, and as a result, localized editions stretch and develop the global concept.

This implies that the professional discourse needs to be conceptualized as a reciprocal process and that the one-directional arrows in Figure 1 need to be replaced by two-directional ones. Semiotics predicts that the development and articulation of the global campaign concept will largely be a function of the meaning attached to the localized discourse by the audience (the arrow running from localized discourse to concept to identity) instead of the other way around. This is the key to explaining the existence of localized "global" brand identities and to explaining unexpected developments in a global campaign.

The concept of a global brand identity and the concept of the customer, moreover, are seemingly unrelated. As we already observed, there is extensive research among target groups to guide the rhetorical design process, but the global brand identity is not modelled as a function of the customers' interpretation processes. A cognitive 
semiotic approach stresses this relation. It determines the concept of a global brand identity as a set of beliefs, opinions and attitudes attributed to the brand, called "brand associations" in marketing theory (Keller et al., 2012, p. 59). Customers are analyzed in the same terms, hypothesizing their sets of initial beliefs, opinions and attitudes. Customers that interpret their brand contacts, including advertisements, restructure the sets of beliefs, opinions and attitudes they attribute to the brand. This network of localized meanings articulates the global concept, and this is how the managerial concept of the global brand identity is conceptually related to the resulting customers' mental representation of an actual "global" brand identity.

The cognitive dynamics of an interpretation process explain how and why the global set of beliefs, opinions and attitudes as conceptualized by the designers (the "unified brand identity" they pursue) is never unaffected by the interpretation process of the individual, local customer. Establishing a brand identity guides customers from their initial position towards specific associations. In this process, the characteristics of a resulting "global" brand identity are partly a function of customers' initial beliefs, opinions and attitudes, which are determined by market conditions, former media exposure, demographic culture and a broad set of background variables (compare Fisbein \& Azjen, 2005). A two-sided arrow needs to be added between localized discourse and global brand identity because the resulting global meaning of the brand is not, as the marketing model suggests, determined by an a priori concept, but is the result of associations that the customers attribute to the brand as an effect of the localized discourse in relation to customers' initial characteristics. A resulting "global" brand identity, therefore, will differ between localizations, andbecause this process is reciprocal, it also develops and determines the meaning of the global concept. This explains how campaigns often develop in unforeseen directions.

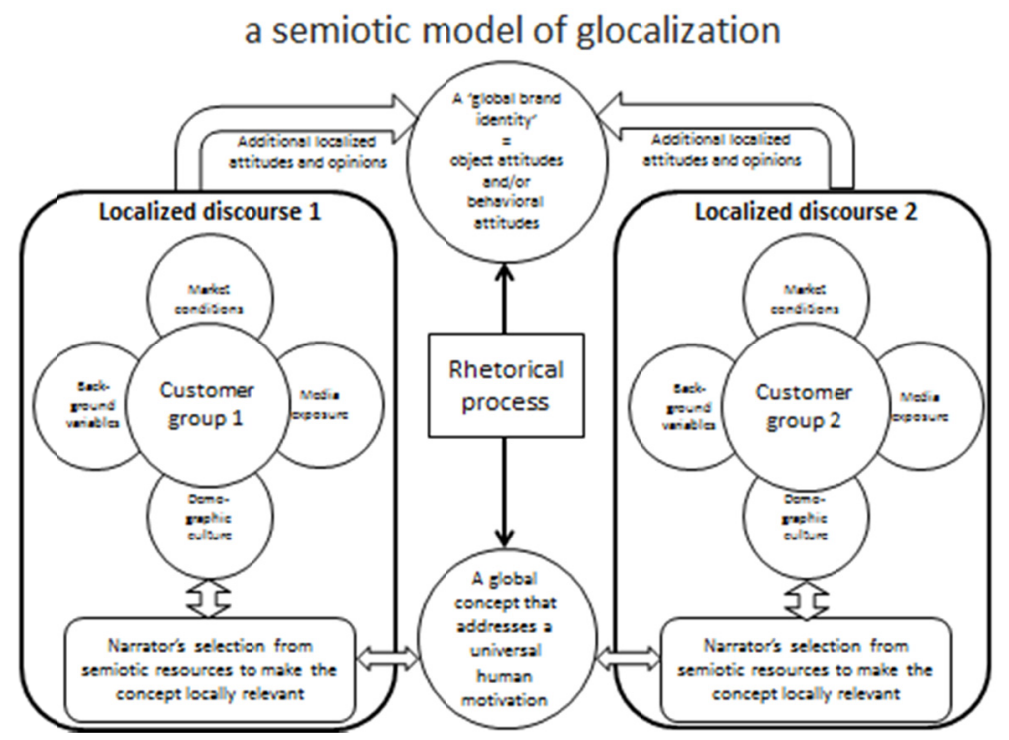

Figure 2. A semiotic model of glocalization

If we add these dimensions to Figure 1, we get Figure 2. The semiotic model does take into account that communication is a transactional reciprocal process, starting with the customers' interpretation instead of the marketers' design and marking a shift from marketer to customer and from sender to audience. This results in a Figure that may look unattractive in its complexity, with the rhetorical process being embedded in a complex system of semiotic dynamics. However, as its application in section 5 will show, analytical tools developed in semiotics make it manageable, and the theoretical and practical added value is significant.

Marketing theorists tend to focus on the design process, that is, on the move from global identity to global concept. Semiotics, on the contrary, focuses on two distinguishable but connected relations. Firstly, it focuses on the reciprocal relation between localized discourse and the global concept. It understands the global concept as a constraint on the semiotic choices in constructing the localized discourse, but at the same time constructs the meaning of the global concept as a function of the meaning attached to the localized discourse. What semiotics adds to brand theory are tools to identify semiotic resources with meaning potentials that are theoretically related to audience characteristics (Kress, 2010, pp. 84-92). 
Secondly, it focuses on the relation between the meaning attached by customers to the localized discourse and the global brand identity. It understands the global brand identity as a point of departure for shaping the actual brand identity, which is the customer's localized mental image of the global brand. Semiotic analysis adds to brand theory tools to articulate the global brand identity in terms of customers' cognitions that differ among localized audiences (Van den Hoven, 2015, pp. 34-86).

To illustrate the application of the semiotic model, we have analyzed localized editions of the global narrative in the Snickers campaign "You're not you when you're hungry." In section 4, we briefly introduce the campaign, focusing on the relation between the global concept and the framing of localization by means of the global concept. In section 5, we focus on the two semiotic relations mentioned above. We analyzed two localized discourses in terms of the choices made from the semiotic resources, and we interpreted the customers' localized mental image of the global brand identity in relation to the professional a priori conceptualization of the global brand identity.

\section{The Rhetorical Challenge of the Snickers Campaign}

When the Mars Company decided to reposition its Snickers brand as "the hunger-busting solution to make sure you stay on top of your game," its creatives developed a global concept, in which Snickers is portrayed as "the bar of substance that sorts you out." Its slogan "You're not you when you're hungry" determines that advertisements will be dominated by a narrative rhetorical device (Van den Hoven, 2015, pp. 118-169). The slogan emphasizes the complication that drives the narrative forward: something goes wrong and what to do next? (Note 3)

We selected this campaign to demonstrate the added value of the semiotic model because it presents a relatively clear case. Snickers is a typical product brand: Its brand equity depends on one product, and product use is about the same over cultures, which allows us to model differences in brand associations as predominantly being the result of brand communication.

In 2010, the campaign's first commercial was launched in the USA as a Super Bowl commercial. The American actress Betty White, born in 1922, struggles with a bunch of football players in the field and even gets tackled down into the mud. Someone hands her a Snicker bar. All of a sudden Betty turns into this energetic young male football player, ready to receive the ball. Finally the ball is caught by Abe Vigoda, born in 1921, falling down and saying "That hurts. You're not you when you're hungry." Then the slogan is projected and the final shot is the chocolate bar with a slogan "Snickers satisfies."

The successful campaign team later developed many new and creative formats, predominantly using social media to communicate this global "You're not you when you're hungry" concept. Commercials following the Betty White narrative, however, were leading in the first period. At the 2013 Association of National Advertiser's annual conference in Phoenix, David Lubars, BBDO chairman and chief creative officer for North America, and Debra Sandler, Mars Chocolate North America President, explained that the Snickers team allowed local markets to adjust the ads. "When each region gets to do their own executions [...] then they feel an ownership of it." This may seem straight forward, following the linear three-step Wind et al. model, but from a semiotic point of view it implies a complicated reciprocal process.

When one projects the semiotics of the fully determined story (the Super Bowl commercial, for example) onto the semiotically undetermined and underspecified global concept (captured in a "narrative slogan"), the gap between these two discourses becomes obvious. The number of paradigmatic choices made in producing the Super Bowl commercial is enormous. These choices invite the audience to construct meanings that were not and could not be implied in the global concept a priori; on the contrary, each specific edition developed the concept. For each element in this dynamic process of meaning construction, the global coordinators of the campaign (Mars Company and BBDO) could only determine its relation to the global concept afterwards. As we will see in section 5 , this not only resulted in locally differentiated "global" brand identities, butit also sent the development of the campaign into new, almost certainly unexpected directions.

We examined Snickers television commercials that were shown between 2010 and 2012. A large number of editions were broadcast in an even larger number of territories: at least 80 . In a post-hoc reconstruction, the initial narrative can be analyzed as having the following elements: A well-known protagonist (a celebrity) performs in a hyperbolically, hilariously inadequate fashion without being aware of it (complication). When given a Snickers bar by someone else (transference), he or she changes physically into another "common" person (struggle) and performs adequately (recognition). It turns out that this storyline is "global." In 11 territories (five of which used the same clip with language adaptations), even the activity was kept more or less similar: a female protagonist playing American football or soccer. We focused on seven of these commercials (Note 4). 
The global narrative includes an articulated kind of incongruity-resolution humor (Raskin, 1985), related to the concept of celebrity. Humor as a phenomenon is universal across cultures, but cultures differ in the kind of humor that is appreciated in specific situations, especially when incongruity-resolution humor goes together with violence. Gulas \& Weinberger (2006) reported research indicating that several demographic factors determine appreciation of specific humorous content and thatthe perception of humor differs with age, gender, educational level, culture and subculture (Gulas \& Weinberger, 2006, p. 50). Alden, Hoyer, \& Lee (1993) examined the content of humorous television advertising in four national cultures: Korea, Germany, Thailand and the United States. They found that the specific content of humorous advertising is variable across cultures. Crawford et al. (2009), comparing television commercials using humor in USA, Australia and the PRC, found that incongruity-resolution humor is universal but that the use of aggression, as a humor theme, varies per cultural context. The perception of fame in different social realms, as well as the etiquette on behavior towards famous people, also differs between cultures, roughly along similar major normative dimensions as those Alden et al. (1993) found to determine humor content.

The rhetorical challenge of the campaign was to globally develop the primary brand association of "a hunger-busting solution," to maintain the general narrative concept in the campaign and simultaneously to localize the articulated incongruity-resolution humor in an attempt to employ it in a culturally acceptable way. The USA and the PRC differ significantly on cultural dimensions (Note 5). This resulted in substantial "adaptations" (or rather "interpretations," in semiotic terms), affecting prominent secondary associations as elements of the "global" brand identity.

\section{A Semiotic Analysis of the American and a Chinese Edition}

To demonstrate the added value of the semiotic model, we compared the original Betty White commercial with the first Chinese localized edition with Jiang Mengjie, to see how the relation between the global narrative concept and the localized cultures developed. We positioned our analyses against the background of the other commercials in which a female protagonist plays football or soccer.

Analytically, one can distinguish between translation and transformation: translation employs a different sign to evoke a largely equivalent meaning, and transformation employs a different sign to evoke a different meaning. This distinction is purely analytical; on some level of specificity, a different sign always implies a different meaning. In our case, however, we can maintain that two different signs can be considered equivalent when they guide the relevant audiences to attribute-equivalent brand associations, and in this case we speak of translation. When the signs guide the localized audiences to a relevant difference in brand associations, we speak of transformation. In the following, we will demonstrate how semiotic analysis reveals significant transformations. These transformations imply stretching the global campaign concept.

We will discuss two paradigmatic and one syntagmatic difference, which we consider significant for the reciprocal relations between localized discourse and the global concept: firstly, the replacement of Betty White by Jiang Mengjie, a replacement with major implications; secondly, the reaction of other players to the inadequately behaving protagonist; and thirdly, the syntagmatic choice to construct a significant difference in length between thematically equivalent shots.

\subsection{Betty White versus Jiang Mengjie}

Decisive for the success of the American Super Bowl commercial was the casting of Betty White, as this casting evokes a specific layer of meaning that is missing from the Chinese protagonist. Born in 1922, Betty White

evokes the stereotype of an elderly female, with the negative connotations the American youth culture tends to attach to female aging (Butler, 1975, p. 12). This first layer of meaning fits straight forwardly into the narrative: an old lady cast as a player on the American football field creates a hyperbolic incongruity that requires resolution. Together with the slapstick elements in the scene, it constitutes the humor device that drives the narrative. Making fun of an old female's weakness fits into dominant American cultural values, although it is obviously not politically correct.

In the Chinese edition, the fictional character Lin Daiyu is the main protagonist in the syntagm. The actress Jiang Mengjie is not generally known apart from her playing this character in a television series, so it is only the connotations of the character that are relevant. Almost everyone in China knows Lin Daiyu from Cao Xueqin's novel Dream of the Red Chamber, one of China's four great classic novels. Suffering from a respiratory ailment, she is sickly but beautiful. She is the reincarnation of a flower, and in the ad she is surrounded by floating flowers (Cody \& Sprichorn, 2007, p. 372). Making fun of a young female's weakness, again obviously not politically correct, fits into dominant Chinese social values. 
Although the old, popular culture celebrity Betty White has been replaced by a young, high-culture fictional character Lin Daiyu, the first layer of meaning, a hyperbolic incongruity requiring resolution, remains in the Chinese edition. Considered from the perspective of the design process, the adaptation can be motivated and explained predominantly as a cultural translation. Both editions employ the incongruity-resolution humor device, going from the impossible to the possible. A little dialogue with the player confronting the female protagonist provides the punch line that marks the transition from the impossible to the possible (Raskin, 1985). Cultural differences in humor appreciation largely motivate the replacement of the elderly protagonist by a young one, and the replacement of a violent action scene by a lethargic static scene. The modern, popular culture celebrity Betty White is replaced by the classic, high-culture character Lin Daiyu. Betty White is a strong individual; Lin Daiyu is a meme in the collective Chinese memory.

As Chinese people have a notable tradition of respect for the elders, Chinese advertisings show more veneration for history and tradition than American advertisings (Zhou et al., 2005). In the book of filial duty (Chen, 2014), respect for parents and elders is the most stressed point. In the Analects, Confucius formulated rules that children were to follow to fulfill their filial duties (Waley, 2012). The passages are widely quoted in discussions of respectful treatment of parents and elders, roles and duties of adult children and intergenerational relations. American culture is also traditional but endorses independence and promotes equality (Jin, 2014, p. 36). American culture, less respectful of age, may object to the extreme gender inequality in the Chinese edition.

However, this analysis of the adaptation that fits into the translation model is only one part of the story. As soon as we start to analyze the meaning of localized editions from the perspective of the customers' interpretation, we encounter a difference that can only be explained as a major transformation: While the individual refutes her own stereotype most notably in the American edition, the individual entirely confirms it in the Chinese version.

In the Chinese edition, the main character fully confirms the connotations that are attached to her as a weak young woman. As a goalkeeper, Lin Daiyu is merely waiting for the ball. She is unable to catch even the simplest of balls. Although she is not hit, she still falls down unnaturally, noticeably showing her weakness. After she has fallen down, she does not get up immediately but puts the back of her hand on her cheek area, conveying that she is very lethargic. She cries when offended. The token Lin Daiyu entirely confirms the type she represents.

In the American edition, something entirely different happens. The actress and celebrity Betty White denies all connotations that she evokes as a type. This clash between type and token is played out in the commercial when another football player exclaims: "You're playing like Betty White." American viewers (and many others) know Betty White as Rose Nyland from the famous series Golden Girls. She is thought to have had a very active (sex) life, not accidentally producing and presenting USA Betty White's Off Their Rockers, a 2012-2014 television series pranking members of the younger generation by violating all prototypical characteristics of the elderly. In acting this out, she tries hard to run, falls down into the mud and is trampled by a player with an imposing physique. She gets up immediately, however, and walks to the other players, supposedly uninjured, putting her hands on her hips, ready for assertive action. She upturns her face to express her effort not to be considered weak. As a response to "You're playing like Betty White" she immediately responds with "That's what your girlfriend says." All of this is meant to refute the stereotype of the old and the weak. This layer of meaning is vividly articulated and dominates the discourse. On a secondary level, in sum, the American edition evokes a specific myth (Barthes, 1972, p. 114), namely the myth of countering your stereotype, while the Chinese version evokes a myth of conformism.

This first adaptation demonstrates our theoretical point that the meaning of the global concept is indeed articulated or even constructed in the localized discourse. The mythical meaning cannot have been inscribed into the abstract concept in advance, simply because it is the result of this very specific paradigmatic choice, evoked by casting these actresses and their playing it out. The consequences of this for the development of the global concept as well as for the localized "global" brand identity cannot be foreseen, but they can only be accepted afterwards in the context of developing editions.

When we project this major transformational difference against the background of the other editions, we can conclude that the original Betty White edition and the Chinese edition are the extremes on a scale. Close to the Chinese edition is the edition used in Taiwan, Singapore, Malaysia, the Philippines and Indonesia, in which the female character is also a goalkeeper, young, passive and played by a relatively unknown actress while the male counterpart is a celebrity. In handling the repartee, however, she is more assertive than Daiyu. The Korean and Japan editions show young women, both famous celebrities, who do not really participate in the game but play on their personal image (Goo Hara butt-shaking and Erika Sawajiri behaving naughty) and tend to dominate the confrontation with the other players. The Hong Kong edition and the Egypt edition come close to the American 
one, starring famous elderly ladies, though none of them denies her stereotype as clearly as Betty White.

The semiotic analysis highlights this difference because it relates localized versions to each other instead of understanding the localized editions as having merely been derived from a global concept. In this direct comparison, it also becomes clear that the replacement implies a major transformation in values, the details of which we will discuss below, taking into consideration the other two adaptations.

\subsection{Individual Problem versus Social Problem}

The failure of the protagonist in a collective game like American football or soccer asks for a response that results in the narrative stage of transference. One of the by standers needs to restore the balance; he diagnoses the problem and offers the Snickers as a solution. Before this moment, however, the problem has been socially contextualized.

In the American edition, after Betty White has got up, some other players group together, and she approaches them. Together they form a circle, expressing their intention to discuss the situation. One tall player bows down and asks for an explanation, trying to discuss it with her at eye level. She is almost included in the circle, addressed as an equal with a problem (Figure 3a). After she verbally abuses the tall player, his response is one of surprise and laughter (Figure $3 b$ ).
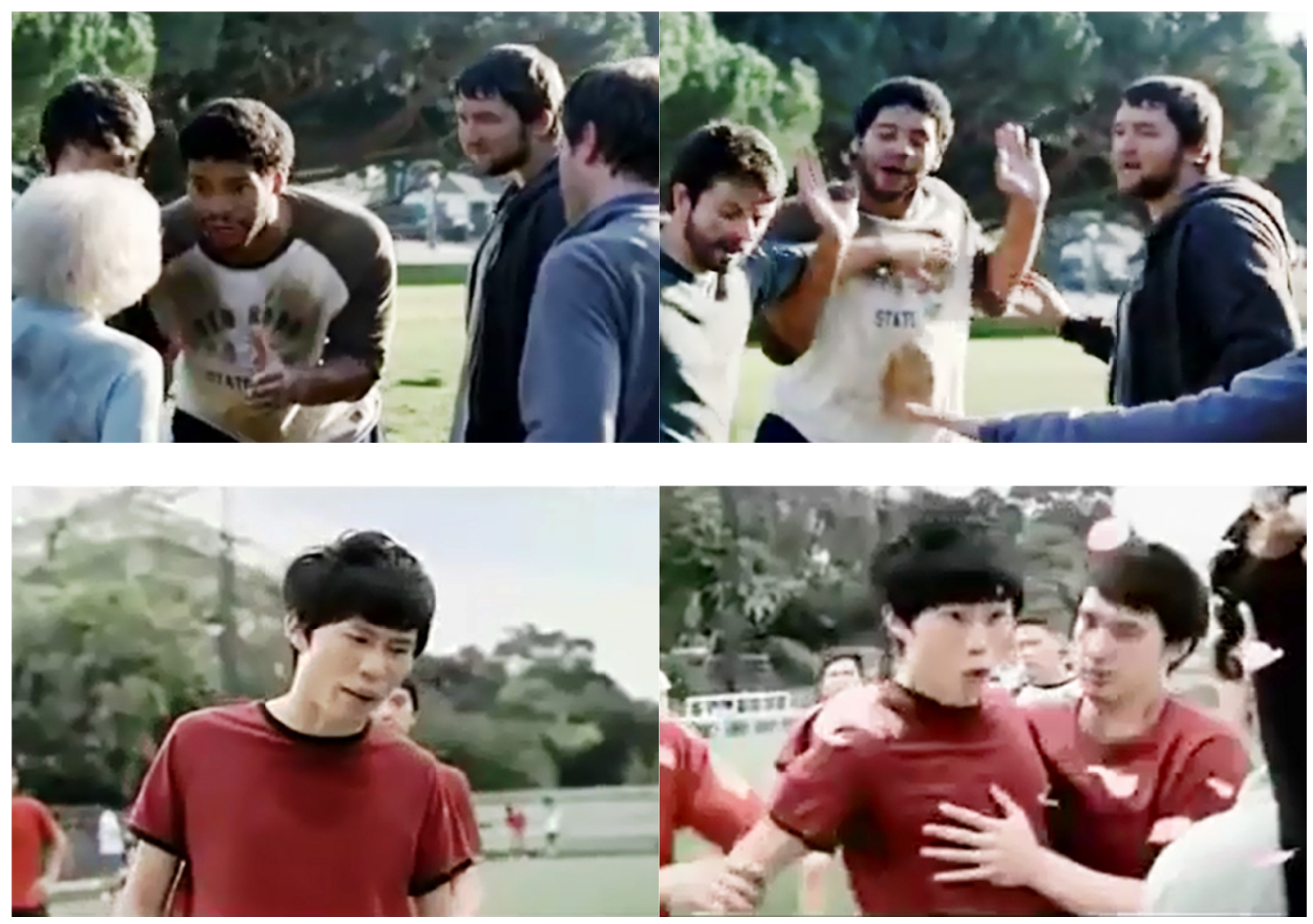

Figure 3. Responses of the others

Source: https://www.youtube.com/watch?v=uA7-31Cxc2I, https://www.youtube.com/watch?v=LvdUIjvviZ4

In the Chinese edition, while the weak player is still down, we get a sequence of six shots: (1) (middle close-up) two players look with strong disapproval at something out of the frame (obviously Daiyu); (2) (middle shot) Daiyu is down; (3) (middle close up) a very aggressive looking player approaches something out of the frame; only at the end of the shot does Daiyu enter the right side of the frame from below, obviously standing up (Figure 3c); (4) (reverse shot, over the boy's shoulder) Daiyu is in the middle of the frame, crying; (5) (reverse shot) the boy attacks her but is held back by the others (Figure 3d); (6) (middle close up) Daiyu is crying. Then another, slightly older player approaches her to offer the solution. 
The body language of the aggressive player, chin down, signals a negative, judgmental, aggressive attitude, followed by chin jutting forward, signaling superiority, arrogance, power and aggression. In sum, strongly construed by cinematographic means, the response is aggressive, blames her and isolates her from the others.

This transformation fits into the mythical meanings that we just discovered. Betty White, refuting what she looks like, is much closer to the others than Daiyu, confirming her identity. More important, however, is that the conflict as such is firmly embedded in a cultural value system. Western cultures emphasize individual performance, and America, as an individualistic country, is inclined to treat people as individuals. When somebody does something wrong, it is his or her own problem, and White is approached as an individual with a problem. Eastern cultures value harmonious relationships, with the remarkable effect that an individual who disturbs collective harmony has to face collective indignation (Hampden-Turner \& Trompenaars, 1993; Nisbett \& Masuda, 2003). In China, as a collectivistic country, when somebody does something wrong, this is a social problem. It makes others angry.

More detailed cinematographic analysis than we can present here supports how the localized audience in the American edition is guided towards positioning the brand product as a means to energize the individual, taking up her tasks, in a position to encounter the other individual, who may fail next, as Abe Vigodadoes. In the Chinese edition, the brand product is positioned as a means to restore social harmony. The action is completed immediately after Daiyu's transformation into a young male; this character's role is then irrelevant.

\subsection{Action versus Lethargy}

To evaluate cultural adaptations, it is important to consider how messages are communicated to the audience through visual production techniques (Cho et al., 1999). Here we only analyze the syntagm (Table 1).

The main difference in the unfolding narrative is between scenes 2-4 and 7. The American edition emphasizes the individual action. The tackle scene, with Betty White falling full length into the mud, takes eight seconds, whereas it takes only four seconds for Lin Daiyu to fall down slowly without clear cause in the Chinese edition. The American edition shows the tackling in a dynamic medium shot, whereas the Chinese edition shows the falling in a static long shot of the one individual. In the American edition, the exposition of the conflict takes eight seconds, whereas in the Chinese edition, the conflict scene, with the abusive aggressive player, gets all the emphasis and takes eleven seconds. This is repeated in the scene in which the player accepts and eats the Snickers. Accepting and eating the chocolate bar is a minor moment in the American syntagm, immediately continuing the action. In the Chinese syntagm, the restoration of social harmony is the end of the narrative and takes eight seconds. The American edition emphasizes the action; the Chinese edition emphasizes the result of getting and eating the product. The final scene, which is not part of the narrative anymore, reflects this emphasis on the product. In the American ad, the Snickers product and the campaign slogan are conveyed in two seconds, but in Chinese ad this takes four seconds (Note 6).

Table 1. Syntagmatic Structure in Scene and Length of Scenes

\begin{tabular}{llll}
\hline & Scenes & American ad & Chinese ad \\
\hline 0 & Blank & $1 \mathrm{sec}$ & $1 \mathrm{sec}$ \\
1 & The overall field view & $1 \mathrm{sec}$ & \\
2 & Player (old woman/woman) plays ball and falls down & $8 \mathrm{sec}$ & $4 \mathrm{sec}$ \\
3 & Player tries to stand up and explain & $8 \mathrm{sec}$ & $11 \mathrm{sec}$ \\
4 & Player accepts Snicker and eats & $3 \mathrm{sec}$ & $7 \mathrm{sec}$ \\
5 & Player becomes strong male & $3.5 \mathrm{sec}$ & $3 \mathrm{sec}$ \\
6 & Other weak player & $3.5 \mathrm{sec}$ & \\
7 & Snickers product and campaign slogan & $2 \mathrm{sec}$ & $4 \mathrm{sec}$ \\
\hline & Total & $30 \mathrm{sec}$ & $30 \mathrm{sec}$ \\
\hline
\end{tabular}

When we try to formulate the impact of the differences between the American and the Chinese interpretation of the abstract global concept, we may conclude that, from a designer's point of view, the adaptations may be predominantly translationally motivated. However, from a semiotic perspective, focusing on the hypothetical audience responses, the adaptations imply a significant transformational component. The localized discourses convey different stories, communicating different values, positioning the brand in an entirely different value system and guiding the localized audiences towards different secondary brand associations. In the American context, we can hypothesize that the audience will associate the Snickers product brand primarily with hunger-busting solution, and secondarily with popular-culture fame, with slightly controversial behavior, with articulating individuality cashing in on conflict and with strong cocksureness refuting majority opinions. In the 
Chinese context, we can hypothesize that the audience will also associate the Snickers product brand primarily with hunger-busting solution, but secondarily with traditional Chinese core values, with behaving very conventionally by restoring harmony and with serving collectivism confirming your membership (Note 7).

\section{Conclusion}

Our study illustrates the advisabilityof filling up the semiotic gaps left by a popular marketing model for global advertising, showing that a seemingly linear three-step model actually implies several interactive processes. The semiotic model provides tools to compare localized editions of a global campaign in a meaningful way in addition to understanding the localized editions as derived from an underspecified global concept. This makes it possible to trace the different choices made from the available semiotic resources and to develop specific hypotheses about moments in which it is not merely translation that takes places but also transformation. As a result, one can connect the concept of a professionally designed global brand identity with the concept of brand identity that is the result of an audience's interpretation processes. From a semiotic point of view, the a priori global concept as it emerges from the professional design discourse interpreted in the dynamics of professional interaction, needs to be evaluated with respect to a "network" of localized "global" brand identities as they emerge from the localized discourses interpreted in the dynamics of customer contacts with the brand.

This semiotic addition to the marketing model explains data from anthropological sources about the actual design and development of campaigns that show complex feedback loops, permanent adjustments of the initial concepts, dominancy of already produced localized discourses as a template for new localizations over the abstract concept and unexpected developments (Note 8). It explains how locally differentiated global brand identities result from strictly governed global campaigns, based on a rather detailed and elaborated narrative, as the Snickers campaign that we analyzed. As we saw, it is exactly the elaborateness of the initial global campaign concept that shuts the door for some translational adaptations and stimulates the dynamics of transformation.

This insight helps us to understand how the Snickers campaign took a rather spectacular turn. It was expected that certain interpretations of the humor device would be appreciated in the one culture but would be culturally unacceptable in another. Had the required adaptations been merely translations, localized editions would indeed not have been interesting and intriguing for other, unintended audiences. The Snickers campaign, however, saw the global concept develop sensationally under the influence of local interpretations because the violent incongruity humor device that is the core of the narrative requires major transformations. This even opened up the narrative, including other scenes for the protagonist to dysfunction. As a result, localized editions were not only appreciated by local target audiences, but they were interpreted as a humoristic allegory of their own reality.

The major transformations had the effect that, for audiences that would have been offended if they had been targeted directly in this way, the humor was now "exotically" contextualized and, therefore, harmless; the commercial was perceived as a humoristic allegory of the reality of the other. This turned out great for the brand. Soon, localized editions became collectors' items among very diverse audiences, including audiences that were supposed to be offended by some editions. The entire campaign transcended cultural glocalization and became a truly global hype. A different reading started to dominate the intended, localized, recognizable narrative. Each edition is interpreted in a comparison relation with other editions, emphasizing enlarged cultural contrasts in a humorous context. One cannot be offended by a discourse that is read as a discourse about the other.

Soon, the global brand management team recognized opportunities to develop the campaign as a transcultural collection of discourses that hyperbolically exploit cultural differences. New editions produced about a specific cultural group are evidently not intended to be just for that group, but are a friendly parody of that group. Collections of editions are published, and so on.

We do not claim that the semiotic model is able to predict these developments. However, it can afterwards help to explain them in a way that the linear marketing model cannot. If abstract global concepts require major transformations in the process of localization, they may develop in ways that cannot be governed a priori by a global brand management team. This is due to the reciprocal relations that are at the core of the semiotic model.

\section{References}

Ajzen, I., \& Fishbein, M. (2005). The influence of attitudes on behavior. The handbook of attitudes, 173-221. Retrieved from https://www.researchgate.net/publication/264000974_The_Influence_of_Attitudes_on_Behavior

Alden, D. L., Hoyer, W. D., \& Lee, C. (1993). Identifying global and culture-specific dimensions of humor in advertising: A multinational analysis. The Journal of Marketing, 64-75. https://doi.org/10.2307/1252027

Barthes, R. (1972). Mythologies (A. Lavers Trans.). New York: Hill and Wang. 
Butler, R. N. (1975). Why survive? Being old in America. New York: Harper \& Row.

Cho, B., Kwon, U., Gentry, J. W., Jun, S., \& Kropp, F. (1999). Cultural values reflected in theme and execution: A comparative study of US and Korean television commercials. Journal of Advertising, 28(4), 59-73. http://dx.doi.org/10.1080/00913367.1999.10673596

Cody, G. H., \& Sprinchorn, E. (Eds.). (2007). The Columbia encyclopedia of modern drama (Vol. 2). New York: Columbia University Press.

Crawford, H. J., Gregory, G. D., Munch, J. M., \& Gulas, C. S. (2009). Humor in cross-cultural advertising: comparing Australia, the United States and the People's Republic of China. In Cross Cultural Research Conference. Retrieved from http://corescholar.libraries.wright.edu/marketing/22

Elpers, J. L. W., Mukherjee, A., \& Hoyer, W. D. (2004). Humor in television advertising: A moment-to-moment analysis. Journal of Consumer Research, 31(3), 592-598. https://doi.org/10.1086/425094

Gulas, C. S., \& Weinberger, M. G. (2006). Humor in Advertising: A Comprehensive Analysis.

Hall, E. T. (1976). Beyond culture. New York: Anchor.

Keller, K. L., Apéria, T., \& Georgson, M. (2012). Strategic brand management: a European perspective (2nd ed.). New Jersey: Kevin Prentice Hall Financial Times.

Kobayashi, K. (2012). Corporate nationalism and glocalization of Nike advertising in "Asia": Production and representation practices of cultural intermediaries. Sociology of Sport Journal, 29(1), 42-61. http://dx.doi.org/10.1123/ssj.29.1.42

Kress, G. (2010). Multimodality.A social semiotic approach to contemporary communication. London: Routledge.

Lin, S., Van den Hoven, P., \& Zhao, X. (2012). A different smile, a different story: global advertising adaptation for Chinese consumers. Tilburg Papers in Culture Studies 32. Retrieved from https://www.tilburguniversity.edu/upload/714f8e88-8554-4c1d-bad1-ae8ffe4b2921_tpcs\%20paper32.pdf

Nixon, S. (2003). Advertising cultures: gender, commerce, creativity. Thousand Oaks, California: Sage. https://doi.org/10.4135/9781446218839

Oswald, R. L. (2015). Creating Value, The Theory and Practice of Marketing Semiotic Research. Oxford: Oxford University Press.

Raskin, V. (1985). Semantic mechanisms of humor. Boston: D. Reidel Publishing Company. https://doi.org/10.1007/978-94-009-6472-3_4

Rossolatos, G. (2015). Handbook of Brand Semiotics. Kassel: Kassel University Press.

Van den Hoven, P. (2015). Gold Mining. The art of rhetorical discourse analysis. Xiamen: Xiamen University Press.

Vanauken, B. (2003). Brand Aid: An Easy Reference Guide to Solving Your Toughest Branding Problems and Strengthening Your Market Position. AMACOM/American Management Association.

Weinberger, M. G., Gulas, C. S., \& Weinberger, M. F. (2012). The Role of Culture in Advertising Humor. Handbook of Developments in Consumer Behaviour, 83-117. https://doi.org/10.4337/9781781005125.00009

Wind, J., Sthanunathan, S., \& Malcolm, R. (2013). Great Advertising Is Both Local and Global. Harvard Business Review. Retrieved from https://hbr.org/2013/03/great-advertising-is-both-loca

Zaltman, G. (2003). How Customers Think: Essential Insights into the Mind of the Markets. Boston: Harvard Business School Press.

Zaltman, G., \& Zaltman, L. (2008). Marketing Metaphoria: What Deep Metaphors Reveal about the Minds of Consumers. Boston: Harvard Business Press.

Zhao, X., \& Belk, R. W. (2008). Politicizing consumer culture: Advertising's appropriation of political ideology in China's social transition. Journal of Consumer Research, 35(2), 231-244. https://doi.org/10.1086/588747

Zhou, S., Xue, F., Xue, F., \& Zhou, P. (2005). Visual differences in US and Chinese television commercials. Journal of Advertising, 34(1), 112-119. http://dx.doi.org/10.1080/00913367.2005.10639182 


\section{Notes}

Note 1. Semiotics has become a familiar concept in the practice of and reflection on brand communication. The annual Semiofest conference is a lively meeting of marketers, creatives and academics. Laura Oswald's book Creating Value, the theory and practice of marketing semiotics research (Oswald, 2015) has been widely noticed in marketing practice. In the academic field, an academic handbook has been published (Rossolatos, 2015) and a journal has been established: International Journal of Marketing Semiotics: http://ijmarketingsemiotics.com/. This rise of semiotics in this field is no coincidence as it fits into the shift from marketer to customer, from sender to audience. The connection between the often rather impervious academic dissertations and the practitioners, however, requires improvement. This is why we have based ourselves on a marketer's model in this article and have avoided references to academic semiotic debates.

Note 2. Anthropological studies (Nixon, 2003; De Waal Malefyt et al., 2012), however, show that there is in fact a complex interaction between all stages of a campaign.

Note 3. Narrative theory usually distinguishes five stages in the syntagm of a narrative: preparation (initial stage of balance); complication (disturbance of this balance; here: hunger, weakness); transference (some force taking up the assignment of restoring the balance); struggle (here: supplying and eating a Snickers bar); recognition (stage of punishment and reward; here: transforming into a strong and energetic person). The narrative leads to an epilogue, which is the campaign slogan (Van den Hoven, 2015, pp. 118-126).

Note 4. The US edition with Betty White (born 1922); the Hong Kong edition with Lee Heung-Kam (born 1932); the Egyptian edition with Mimi Gamal (born 1941); the Chinese edition with the young character Lin Daiyu, played by a relatively unknown young actress, 蒋梦婕 (Jiang Mengjie, born 1989); the edition used in Taiwan, Singapore, Malaysia, Philippines and Indonesia with a young actress unknown to us that looks like a geisha; the Korean edition with Goo Hara (born 1991) ; the Japanese edition with Erika Sawajiri (born 1986).

Note 5. On Hofstede's dimensions, for example, USA/China: power distance 40/80, individualism 91/20, masculinity $62 / 66$, uncertainty avoidance $46 / 30$, long-term orientation $26 / 87$, indulgence $68 / 24$. One needs to be careful interpreting any characterizations of Chinese culture, especially its youth culture, as this is developing extremely fast. Campaign designers tend to apply somewhat outmoded views.

Note 6. When we project the comparative analysis of these two ads against the background of the other five editions, the articulated characteristics of the Chinese edition become even more manifest.

Note 7. It is striking how similar these findings are to the findings in a study comparing 1930 American and Chinese Coca-Cola ads (Lin et al., 2012). The American version predominantly communicates that drinking Coca-Cola is a means to express your individuality. The Chinese ad predominantly conveys that drinking Coca-Cola is an experience that is compatible with the social group values you want to maintain.

Note 8. Nixon (2003), Kobayashi (2012), and in particular De Waal Malefyt et al. (2012) provide in-depth anthropological analyses of the complex interactions in the design process.

\section{Copyrights}

Copyright for this article is retained by the author, with first publication rights granted to the journal.

This is an open-access article distributed under the terms and conditions of the Creative Commons Attribution license (http://creativecommons.org/licenses/by/4.0/). 